\title{
Retraction
}

\section{Retraction: A novel function of poly(ADP-ribose) polymerase-1 in modulation of autophagy and necrosis under oxidative stress}

\author{
Q Huang, Y-T Wu, H-L Tan, C-N Ong and H-M Shen \\ Cell Death and Differentiation (2010) 17, 1944; doi:10.1038/cdd.2010.121; published online 24 September 2010
}

Retraction to: Cell Death and Differentiation (2009)16, 264-277; doi: 10.1038/cdd.2008.151; published online 31 October 2008

The authors would like to retract the above article.

Recently, the authors were alerted by the journal's editors to some discrepancies in their data. After a careful review, sufficient errors and mistakes were found that, although the authors still believe the conclusions of the paper to be valid, all the authors agreed to retract this article so as not to leave potentially misleading data in the literature.

The authors would like to offer their sincere apologies to the readers for these errors and mistakes. 